\title{
SOCIOLINGUÍSTICA E POLIITICA LINGUÍSTICA: OLHARES CONTEMPORÂNEOS
}


Raquel Meister Ko. Freitag

Cristine Gorski Severo

Edair Maria Görski

(organizadoras)

\section{SOCIOLINGUÍSTICA E POLIITICA LINGUÍSTICA: OLHARES CONTEMPORÂNEOS}


Sociolinguística e política linguística: olhares contemporâneos

(c) 2016 Raquel Meister Ko. Freitag, Cristine Gorski Severo, Edair Maria Görski (organizadoras) Editora Edgard Blücher Ltda.

\section{Blucher}

Rua Pedroso Alvarenga, 1245, $4^{\circ}$ andar

04531-934 - São Paulo - SP - Brasil

Tel 5511 3078-5366

contato@blucher.com.br

www.blucher.com.br

Segundo Novo Acordo Ortográfico, conforme 5. ed. do Vocabulário Ortográfico da Língua Portuguesa, Academia Brasileira de Letras, março de 2009.

É proibida a reprodução total ou parcial por quaisquer meios sem autorização escrita da Editora.

Todos os direitos reservados pela Editora

Edgard Blücher Ltda.
Dados Internacionais de Catalogação na Publicação (CIP) - CRB-8/7057

Freitag, Raquel Meister Ko.

Sociolinguística e política linguística: olhares contemporâneos / Raquel Meister Ko. Freitag, Cristine Gorski Severo, Edair Maria Görski (organizadoras). - São Paulo: Blucher, 2016. 264 p.; PDF.

Bibliografia

ISBN 978-85-8039-146-6 (e-book)

ISBN 978-85-8039-145-9 (impresso)

Open Access

1. Sociolinguística I. Título II. Severo, Cristine Gorski

III. Görski, Edair Maria

$16-0173$

CDD 410
Índice para catálogo sistemático:

1. Sociolinguística 


\section{Sumário}

APRESENTAC̣ÃO

PARTE I - VARIAC̣ÃO E MUDANÇA:

ABORDAGENS TEÓRICAS, METODOLOGIA

DE COLETA DE DADOS E FENÔMENOS

LINGUÍSTICOS EM FOCO

19

1. AS VOGAIS MÉDIAS [e] E [o]:

UM ESTUDO FONÉTICO-ACÚSTICO

E COMPARATIVO

21

1.1. INTRODUÇÃO

1.2. PRINCÍPIOS ACÚSTICOS DA FALA

1.3. A CLASSIFICAÇÃO DAS VOGAIS DO PORTUGUÊS BRASILEIRO

1.4. METODOLOGIA

1.5. DESCRIÇÃO E ANÁLISE ACÚSTICA DOS DADOS

1.6. ANÁLISE ACÚSTICO-COMPARATIVA ENTRE FALANTES SERGIPANOS E CAPIXABAS 
1.7. CONSIDERAÇÕES FINAIS

1.8. REFERÊNCIAS

2. CORRELAC̣ÃO ENTRE ORDEM VERBO-SUJEITO

E SUJEITO NULO: A TRAJETÓRIA DA

MUDANÇA NO PORTUGUÊS

DE SANTA CATARINA

35

2.1. INTRODUÇÃO

2.2. O PARÂMETRO DO SUJEITO NULO E A ORDEM

DO SUJEITO NO PORTUGUÊS BRASILEIRO

2.2.1. A ORDEM DO SUJEITO EM SENTENÇAS

DECLARATIVAS

2.2.2. O SUJEITO NULO

44

2.3. DESCRIÇÃO E ANÁLISE DOS RESULTADOS

46

2.3. 1. A ORDEM DO SUJEITO E O SUJEITO PRONOMINAL

48

2.3.2. A FORMA DE REPRESENTAÇÃO DO

SUJEITO PRONOMINAL

2.4. CONSIDERAÇÕES FINAIS

2.5. REFERÊNCIAS

\section{AMBIGUIDADE ESTRUTURAL E VARIACÃO} NA CONCORDÂNCIA NÚMERO-PESSÓA EM CLIVADAS CANÔNICAS NO PORTUGUÊS BRASILEIRO

3.1. INTRODUÇÃO

3.2. SENTENÇAS CLIVADAS NO PB: AMBIGUIDADE ESTRUTURAL QUE PERMITE VARIAÇÃO NÚMERO-PESSOA ENTRE CÓPULA E O SN CLIVADO

3.2.1. UMA ANÁLISE CARTOGRÁFICA DAS SENTENÇAS CLIVADAS 
3.3.2. UM BREVE PANORAMA DA VARIAÇÃO NAS

SENTENÇAS RELATIVAS DO PORTUGUÊS CULTO

FALADO NO BRASIL

3.4. EM DEFESA DA SOCIOLINGUÍSTICA

EM INTERFACE COM A TEORIA GERATIVA:

A AMBIGUIDADE ESTRUTURAL COMO MOTIVADORA DA VARIAÇÃO DE NÚMERO-PESSOA ENTRE CÓPULA

E SN CLIVADO NAS SENTENÇAS CLIVADAS CANÔNICAS NO PB

3.4.1. JUSTIFICANDO/ADEQUANDO A ANÁLISE DA VARIAÇÃO NAS CLIVADAS CANÔNICAS EM UMA

PROPOSTA DE INTERFACE

3.5. CONSIDERAÇÕES FINAIS 74

3.6. REFERÊNCIAS

\section{VARIAC̣ÃO DISCURSIVA: PROCEDIMENTOS METODOLÓGICOS PARA DELIMITAC̣ÃO DO ENVELOPE DE VARIAC̣ÃO}

4.1. INTRODUÇÃO

4.2. CONTEXTUALIZANDO OS NÍVEIS DE ANÁLISE

4.3. ANÁLISE SOCIOLINGUÍSTICA DE FENÔMENOS DISCURSIVOS

4.3. 1. DELINEANDO O ENVELOPE DE VARIAÇÃO

DE FENÔMENOS DISCURSIVOS: PASSOS INICIAIS

4.3.2. PROCEDIMENTOS PARA DELIMITAÇÃO

DE VARIÁVEIS DISCURSIVAS

4.3.3. CRITÉRIOS PARA DELIMITAÇÃO DE RADs

4.3.3. 1. CRITÉRIO DE UNIDADE FUNCIONAL E DE COMPARTILHAMENTO DE CONTEXTOS DE USO

4.3.3.2. CRITÉRIO DE UNIDADE CONCEPTUAL E CLASSE GRAMATICAL DE ORIGEM 


\subsubsection{SELECIONANDO OS ITENS PARA COMPOR \\ $\bigcirc$ OBJETO DE ESTUDO A PARTIR DA APLICAÇÃO \\ DOS CRITÉRIOS}

4.4. CONSIDERAÇÕES FINAIS 94

4.5. REFERÊNCIAS

94

5. CONSTITUIĈ̃O DE AMOSTRAS SOCIOLINGUÍSTICAS E O CONTROLE DE VARIÁVEIS PRAGMÁTICAS

101

5.1. INTRODUÇÃO

101

5.2. ESTRATIFICAÇÃO SOCIAL

5.3. A EXPRESSÃO DA POLIDEZ E AS VARIÁVEIS

PRAGMÁTICAS

5.4. AMOSTRAS PARA O CONTROLE DE VARIÁVEIS

PRAGMÁTICAS

5.5. CONSIDERAÇÕES FINAIS

110

5.6. REFERÊNCIAS

111

\section{METODOLOGIA DE COLETA DE DADOS EM ESCOLAS DA REDE PÚBLICA E PRIVADA DE ENSINO DE FLORIANÓPOLIS}

6.1. INTRODUÇÃO

6.2. BANCO DE DADOS SOCIOLINGUÍSTICOS

6.3. METODOLOGIA DE COLETA DE DADOS DE TEXTOS ESCRITOS EM ESCOLAS DA REDE PÚBLICA DE FLORIANÓPOLIS

6.4. METODOLOGIA DE COLETA DE DADOS

DE FALA EM COMUNIDADES DE PRÁTICA

EM UMA ESCOLA DA REDE PRIVADA DE ENSINO

DE FLORIANÓPOLIS

6.5. CONSIDERAÇÕES FINAIS

6.6. REFERÊNCIAS

ANEXO 1

ANEXO 2 
$\begin{array}{lr}\text { ANEXO } 3 & 134\end{array}$

$\begin{array}{ll}\text { ANEXO } 4 & 136\end{array}$

7. AVALIAÇÃO E VARIAC̣ÃO LINGUÍSTICA:

ESTEREÓTIPOS, MARCADORES E INDICADORES

EM UMA COMUNIDADE ESCOLAR

7.1. INTRODUÇÃO 139

7.2. FENÔMENOS SOB ANÁLISE 140

7.2. 1. REALIZAÇÃO AFRICADA DE OCLUSIVAS 141

7.2.2. VARIAÇÃO NA PRIMEIRA PESSOA DO PLURAL 142

7.2.3. ALÇAMENTO DE VOGAIS MÉDIAS A ALTAS 142

7.3. O ATHENEU SERGIPENSE 143

7.4. COLETA DE DADOS 145

7.5. RESULTADOS 149

7.5.1. EXPRESSÃO DA $1^{a}$ PESSOA DO PLURAL 150

7.5.2. ALÇAMENTO DAS VOGAIS MÉDIAS 154

7.5.3. REALIZAÇÃO AFRICADA DE OCLUSIVAS

ALVEOLARES SEGUINTES AO GLIDE 155

7.6. CONSIDERAÇÕES FINAIS 157

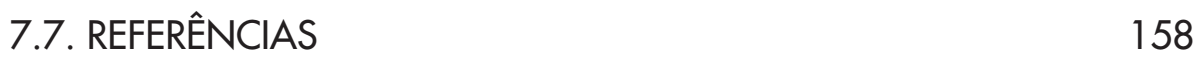

PARTE 2 - POLÍTICA E PLANIFICAC̣ÃO

LINGUÍSTICA

161

8. PROLEGÔMENOS PARA A COMPREENSÃO DOS DIREITOS LINGUÍSTICOS: UMA LEITURA A PARTIR DA CONSTITUIC̣ÃO DA REPÚBLICA FEDERATIVA DO BRASIL

163

8.1. INTRODUÇÃO

8.2. OS MARCOS HISTÓRICO, FILOSÓFICO-JURÍDICO E TEÓRICO DOS DIREITOS LINGUÍSTICOS 
8.2.1. O MARCO HISTÓRICO DOS DIREITOS

LINGUÍSTICOS

8.2.2. O MARCO JURÍDICO-FILOSÓFICO

DOS DIREITOS LINGUÍSTICOS

8.2.3. O MARCO TEÓRICO DOS DIREITOS

LINGUÍSTICOS

8.3. OS DIREITOS LINGUÍSTICOS NO ORDENAMENTO JURÍDICO BRASILEIRO

8.3.1. DIREITO DAS LÍNGUAS

8.3.2. DIREITO DOS GRUPOS LINGUÍSTICOS

8.4. CONSIDERAÇÕES FINAIS

8.5. REFERÊNCIAS

\section{POLÍTICAS PATRIMONIAIS E PROJETOS} NACIONALISTAS: LÍNGUAS E BRASILIDADE EM TELA

9.1. INTRODUÇÃO

9.2. CONTEXTUALIZANDO A PATRIMONIALIZAÇÃO:

ARTICULAÇÃO ENTRE INTELECTUAIS E POLÍTICOS

9.3. A PATRIMONIALIZAÇÃO DA LÍNGUA NAS ESFERAS

INTERNACIONAIS E NACIONAIS

9.4. PROBLEMATIZANDO A PATRIMONIALIZAÇÃO

DAS LÍNGUAS

9.5. CONSIDERAÇÕES FINAIS

9.6. REFERÊNCIAS

\section{EM TERRENO MINADO: INCOERÊNCIAS E CONFLITOS IDEOLÓGICOS NOS DIZERES CIENTÍFICOS E MIDIÁTICOS SOBRE A NORMA DO PORTUGUÊS BRASILEIRO}

10.1. INTRODUÇÃO

10.2. OS CONFLITOS DA NORMA: INCOERÊNCIAS

POLIITICAS E CONCEITUAIS 
10.3. A PESQUISA SOCIOLINGUÍSTICA BRASILEIRA

E A NORMATIZAÇÃO DO PORTUGUÊS

10.4. O DISCURSO DA MÍDIA SOBRE A NORMA:

SENSO COMUM E DISTORÇÃO IDEOLÓGICA

10.5. CONSIDERAÇÕES FINAIS

10.6. REFERÊNCIAS

\section{INGLÊS COMO LÍNGUA FRANCA:} REPRESENTAC̣ÕES E PRÁTICAS DE ALUNOS E PROFESSORES DE LÍNGUA INGLESA NO BRASIL

225

11.1. INTRODUÇÃO 225

11.2. ILF: UMA VARIEDADE OU UMA FUNÇÃO DA LÍNGUA? 226

11.3. IMPLICAÇÕES PEDAGÓGICAS 229

11.4. METODOLOGIA 230

11.5. RESULTADOS E DISCUSSÃO 232

11.6. CONSIDERAÇÕES FINAIS 238

11.7. REFERÊNCIAS 239

ANEXO 1

ANEXO 2

\section{SEXISMO E POLÍTICAS LINGUÍSTICAS} DE GÊNERO

245

12.1. INTRODUÇÃO 245

12.2. MARCAÇÃO DE GÊNERO NO PLANO LEXICAL 246

12.3. MARCAÇÃO DE GÊNERO NO PLANO GRAMATICAL 249

12.3.1. PRONOMES EPICENOS EM INGLÊS

12.3.2. O PRONOME HEN EM SUECO 251

12.4. POSSÍVEIS MUDANÇAS GRAMATICAIS

NO PORTUGUÊS BRASILEIRO 253

12.5. A MARCAÇÃO DE GÊNERO COMO VARIAÇÃO LINGUÍSTICA 
12.6. CONSIDERAÇÕES FINAIS

12.7. REFERÊNCIAS 


\title{
Apresentação
}

\author{
Raquel Meister Ko. Freitag \\ Cristine Gorski Severo \\ Edair Maria Görski
}

Esta coletânea é um dos resultados do desenvolvimento do projeto "Da expressividade na língua ao mal na literatura: bases institucionais de pesquisa do PPGL/UFS”, financiado pelo edital CAPES/FAPITEC/SE n. 06/2012 - Programa de Estímulo a Mobilidade e ao Aumento da Cooperação Acadêmica da Pós-Graduação em Sergipe (PROMOB), que possibilitou a realização de missões de pesquisa, docência e estudos por docentes e discentes do Programa de Pós-Graduação em Letras da Universidade Federal de Sergipe (UFS) e do Programa de PósGraduação em Linguística da Universidade Federal de Santa Catarina (UFSC). No decorrer das missões, foram realizadas ações como o seminário "Sociolinguística e identidade(s)", na Universidade Federal de Santa Catarina, a palestra "Língua, identidade e tradição: entre a sociolinguística e os estudos discursivos", no I Simpósio Transculturalidade, Linguagem e Educação, na Universidade Federal de Sergipe, a "Jornada Sociolinguística de Intercâmbio UFSC e UFS", com o deslocamento de toda a equipe de estudos linguísticos da UFS para na Universidade Federal de Santa Catarina, a oferta da disciplina "Tópicos de descrição do português", no Programa de Pós-Graduação em Letras da UFS, o "I Workshop em Metodologia de Coleta e 
Manipulação de Dados em Sociolinguística”, na Universidade Federal de Sergipe ${ }^{1}$, o curso de extensão "A interface Sociolinguística/Funcionalismo", na Universidade Federal de Sergipe, e a disciplina "Sociolinguística: Interfaces", na Universidade Federal de Santa Catarina.

As trocas promovidas fomentaram discussões que giram, em linhas gerais, em torno de duas questões centrais que se colocam na área: que tendências teóricometodológicas têm sido observadas na sociolinguística brasileira atualmente; e que fenômenos se colocam como questões para as políticas linguísticas brasileiras. Esses questionamentos orientam a distribuição dos trabalhos que compõem este livro em duas partes.

A primeira parte, Variação e mudança: abordagens teóricas, metodologia de coleta de dados e fenômenos linguísticos em foco, reúne sete textos que colocam em perspectiva aspectos de ordem teórico-metodológica e descritiva relacionados à constituição de amostras, delimitação de variáveis e descrição linguística a partir de interfaces teóricas, bem como à aplicação de resultados. Os capítulos estão ordenados contemplando, inicialmente, resultados de estudos fonético-acústico e sintático; seguidos de dois trabalhos que discutem o tratamento de variáveis em uma perspectiva formal e funcional, respectivamente; além de dois capítulos que focalizam a coleta de dados; e, finalizando a primeira parte, tem-se um texto que trata da avaliação social de variantes na comunidade escolar.

No capítulo As vogais médias [e] e [o]: um estudo fonético-acústico e comparativo, Gádisson Souza, Antônio F. de Souza Neto e Raquel Freitag apresentam a descrição de aspectos fonético-acústicos dos sons vocálicos [e] e [o] na fala de informantes sergipanos, especificamente o primeiro e o segundo formantes. A análise do traço acústico F1 e F2 das vogais médias anteriores indica que os falantes sergipanos apresentam uma variação diagenérica, o que pode ser explicado por questões biológicas existentes entre homens e mulheres. O resultado, quando comparado à fala capixaba, evidencia que os falantes sergipanos compartilham as mesmas características, ocupando um espaço vocálico mais reduzido. Os autores salientam a necessidade de ampliação do estudo para as características acústicas das demais vogais do falar sergipano, de modo a contribuir para a descrição do português brasileiro, além de relevar a importância de uma abordagem sociofonética.

Izete L. Coelho, Gésyka M. Silva e Érica Zibetti, no capítulo Correlação entre ordem verbo-sujeito e sujeito nulo: a trajetória da mudança no português de Santa Catarina, examinam duas amostras de cartas pessoais catarinenses (do final do século XIX e meados do século XX), pertencentes ao projeto Para a História do português brasileiro de Santa Catarina (PHPB-SC). Embora a hipótese da existência

1 FREITAG, R. M. Ko. (Org.). Metodologia de coleta e manipulação de dados em Sociolinguística. São Paulo: Blucher, 2014. 
de correlação entre as trajetórias de mudança de sujeito nulo > pronominal e de ordem verbo-sujeito > sujeito-verbo não tenha sido totalmente corroborada, os resultados apontam (i) que tal correlação se verifica em construções com verbos transitivos, em ambos os períodos; e (ii) que, independentemente do tipo de verbo, há preferência por sujeito pronominal expresso e pela ordem sujeito pronominalverbo nas cartas do século XX, nas três pessoas gramaticais, mesmo naquelas em que a flexão verbal poderia garantir a interpretação do sujeito nulo.

Marco Antonio Martins e Francisco Iokleyton Matos, no capítulo Ambiguidade estrutural e variação na concordância número-pessoa em clivadas canônicas no português brasileiro, defendem uma base teórica para o estudo da variação sintática, amparada na interface entre a teoria da variação e mudança e a teoria gerativa. A motivação empírica é o contraste observado na possibilidade ou não de concordância entre cópula e SN clivado em sentenças clivadas canônicas e clivadas invertidas no português brasileiro (PB). Os autores defendem que a variabilidade na marcação da concordância nas clivadas canônicas é gerada pela ambiguidade estrutural envolvendo tais construções, que podem ser relativas ou clivadas, diferentemente das clivadas invertidas que só podem estar associadas a uma estrutura de clivada.

No capítulo intitulado Variação discursiva: procedimentos metodológicos para delimitação do envelope de variação, Edair Görski e Carla M. Valle desenvolvem uma reflexão teórico-metodológica acerca do tratamento sociolinguístico dispensado a variáveis discursivas tomadas como objeto de estudo, reforçando a discussão sobre a necessidade de haver critérios claros e articulados para circunscrever o envelope de variação. Sugerindo um roteiro metodológico para orientar o pesquisador no tratamento de variáveis discursivas, as autoras descrevem os passos iniciais de uma pesquisa variacionista com fenômenos discursivos, procedimentos para delimitação de variáveis discursivas e critérios para delimitação de itens discursivos do subgrupo dos requisitos de apoio discursivo (RADs), a serem operacionalizados em uma análise quantitativa multivariada.

O capítulo Constituição de amostras sociolinguísticas e o controle de variáveis pragmáticas, de autoria de Jaqueline Nascimento, Josilene Mendonça, Débora Aguiar e Leilane Ramos da Silva, aborda contribuições do modelo de polidez (BROWN; LEVINSON, 1987) para a compreensão do funcionamento de fenômenos variáveis, considerando coletas de dados baseadas em relações interpessoais. As autoras sugerem que a metodologia de constituição de bancos de dados inclua, juntamente com as variáveis sociais clássicas (idade, sexo/gênero e escolaridade), o controle de variáveis pragmáticas como distância social dos interagentes, relações de poder e grau do custo da imposição. A proposta é ilustrada com a descrição dos procedimentos metodológicos utilizados para a constituição de três amostras de fala centradas em comunidades de práticas sergipanas.

O capítulo Metodologia de coleta de dados em escolas da rede pública e privada 
de ensino de Florianópolis, assinado por Isabel Monguilhott, Gabriela Silvano, Juliana Chagas, Patrícia Ferminio e Rafael Traesel, apresenta dois protocolos de coleta de dados, baseados nas dissertações em andamento de Silvano e Traesel, visando à constituição de uma metodologia padronizada passível de ser aplicada/ replicada com vistas a análises comparativas. O primeiro protocolo é de coleta de escrita em duas escolas da rede pública de Florianópolis; o segundo, de coleta de fala em comunidades de prática com adolescentes de uma escola da rede privada de ensino. Os protocolos são acompanhados de questionários socioeconômicos aplicados a alunos e professores, com o intuito de averiguar em que medida os fatores extralinguísticos influenciam no condicionamento de formas de variação.

Encerrando a primeira parte, no capítulo Avaliação e variação linguística: estereótipos, marcadores e indicadores em uma comunidade escolar, Raquel Freitag, Cristiane de Santana, Thais de Andrade e Valéria Santos Sousa tratam do monitoramento linguístico como uma das estratégias de preservação de faces. Em uma amostra constituída em espaço escolar, em Aracaju-SE, as autoras investigam o comportamento de três variáveis linguísticas distribuídas em uma escala de avaliação social, caracterizadas, respectivamente, como estereótipo (realização africada de oclusivas alveolares seguintes ao glide palatal); marcador), variação na primeira pessoa do plural; e indicador (alçamento de vogais médias a altas). $\mathrm{O}$ resultado evidencia a tensão entre a dinâmica da estrutura da língua e a dinâmica social, especialmente o papel normatizador da escola, que atua na distribuição de frequências dos fenômenos sensíveis à avaliação social, como a variação na realização de oclusivas dentais seguintes ao glide palatal e a variação na primeira pessoa do plural, e também pelo testemunho dos próprios falantes.

$\mathrm{Na}$ segunda parte, intitulada Política e planificação linguística, cinco capítulos evidenciam como a área está problematizando uma série de temas em que as línguas se tornam o lócus de disputas e debates políticos. Os textos se distribuem em torno dos seguintes tópicos: norma, questão jurídica, construção da brasilidade, inglês como língua franca e políticas de identidade de gênero. A abrangência temática revela a possibilidade de diferentes olhares sobre a relação entre língua e política, envolvendo desde os discursos oficiais e estatais, até as práticas educacionais e os movimentos identitários.

Abrindo a segunda parte, o capítulo Prolegômenos para a compreensão dos direitos linguísticos: uma leitura a partir da Constituição da República Federativa do Brasil, de Ricardo Nascimento Abreu, propõe uma aproximação entre Direito e Políticas Linguísticas. Para tanto, o autor analisa o tratamento dispensado à diversidade linguística a partir dos princípios jurídicos brasileiros, focalizando especialmente os discursos de direitos humanos. Por fim, apresenta uma classificação dos direitos linguísticos que seja juridicamente aplicável ao modelo brasileiro, em que os direitos linguísticos são subdivididos em duas 
espécies distintas, a saber: o direito dos grupos linguísticos e o direito das línguas.

Em Politicas patrimoniais e projetos nacionalistas: linguas e brasilidade em tela, Cristine G. Severo analisa o conceito de língua das políticas brasileiras de patrimonialização. A autora faz uma apresentação do percurso histórico envolvendo as iniciativas estatais de preservação dos bens culturais, conferindo atenção especial ao papel dos intelectuais no processo de construção de uma identidade nacional brasileira. Além isso, apresenta e discute os conceitos de patrimônio material e imaterial, de tombamento e de inventário, com fins de contextualizar as línguas nessa chave conceitual. Por fim, a autora problematiza o conceito de língua nessas políticas públicas que, pela objetificação, desvincula língua e sujeitos.

No capítulo Em terreno minado: incoerências e conflitos ideológicos nos dizeres científicos e midiáticos sobre a norma do português brasileiro, Alexandre C. da Silveira, Charlott Leviski, Julia Izabelle da Silva e Cristine G. Severo tecem reflexões sobre a "norma" do português brasileiro a partir de um olhar histórico e linguístico, problematizando a dimensão política desse conceito. Os autores apresentam uma pequena análise que ilustra, por um lado, o processo de construção do discurso científico sobre a norma culta pela Linguística, com enfoque no projeto da Norma Urbana Cultura (NURC); e, por outro lado, o ataque da mídia jornalística aos sociolinguistas. Tal comparação revela contradições, tensões e disputas em torno da norma do português brasileiro, sinalizando para a dimensão política e tensa que permeia epistemologias, documentos oficiais da educação nacional e apreciações midiáticas.

Jeová A. Rosa Filho, Mayara Volpato e Gloria Gil investigam as representações de professores e alunos acerca da língua inglesa no capítulo Inglês como língua franca: representações e práticas de alunos e professores de língua inglesa no Brasil. Para tanto, discutem o conceito de Inglês como Língua Franca (ILF) a partir do fenômeno da globalização, propondo um olhar intercultural e transfronteiriço de língua. A análise das representações é feita a partir da aplicação de questionários para alunos e professores de inglês do curso extracurricular da UFSC. Os resultados revelam posicionamentos contraditórios entre alunos e professores no que diz respeito à ideia de falante nativo como modelo de proficiência. Além disso, os autores também consideram o papel do material didático na (des)construção desse modelo.

Concluindo a segunda parte, em Sexismo e políticas linguísticas de gênero, Guilherme Mader e Cristine G. Severo tematizam a possibilidade de planejamento político de alterações gramaticais na língua, com enfoque na flexão de gênero. Segundo os autores, esse tema por vezes é visto com certo ceticismo, pois haveria uma tendência de se considerar as estruturas gramaticais de uma língua como fortemente resistentes à manipulação intencional por parte dos falantes, sendo 
que as mudanças gramaticais ocorreriam de maneira vagarosa e "natural", por meio de processos de gramaticalização. Os autores problematizam esse caráter hermético da gramática a partir da análise de ocorrências de variação na marcação de gênero. A conclusão indica que, embora infrequentes, as variações gramaticais iniciadas conscientemente podem sinalizar para percursos de mudança. No caso em questão, tais mudanças seguiriam na direção de se evitar o uso do masculino genérico.

As trocas propiciadas pelas missões de estudo, pesquisa e docência culminam com olhares contemporâneos sobre os campos da Sociolinguística e da Política Linguística. Esperamos que nossa experiência seja instigadora para fomentar mais trocas, rumo ao fortalecimento desse campo do saber. 